Original Research

\title{
Nitrogen Utilization Characteristics and Their Influence on Groundwater in the Weishan Irrigation Region
}

\author{
Zhiqiang Zhao ${ }^{1,3}$, Zhifeng Jia ${ }^{1,2,3 *}$, Zilong Guan ${ }^{1,3}$, Feimin Zheng', \\ Tingting Wei, ${ }^{1,3}$ Danying Wang ${ }^{1,3}$ \\ ${ }^{1}$ School of Water and Environment, Chang'an University, Xi' an 710054, China \\ ${ }^{2}$ Institute of Water and Development, Chang'an University, Xi' an 710054, China \\ ${ }^{3}$ Key Laboratory of Subsurface Hydrology and Ecological Effects in Arid Region, Ministry of Education, \\ Chang'an University, Xi' an 710054, China
}

Received: 4 January 2020

Accepted: 16 March 2020

\begin{abstract}
In agricultural production, the main cause of groundwater pollution has been the leakage of total Nitrogen (TN) caused by excessive water and fertilizer application. In this study, an experiment combining a field and indoors was used to seek optimal coupling scheme and prevent groundwater pollution caused by excessive fertilization. Results showed that in recent years, groundwater quality has been deteriorating, and nitrate levels have increased by approximately three times (2014-2016). The TN accumulated significantly in a different soil layer, along with crop growth. The $\mathrm{N}$ accumulated mainly in the bottom of the studied soil layer $(80-160 \mathrm{~cm})$ over time. Under different water fertilizer treatments, the crop yield, leakage, and $\mathrm{N}$ use efficiency (NUE) were obviously various. The effect of irrigation water quantity was more significant for $\mathrm{N}$ leakage than fertilizer $(\mathrm{P}<0.05)$, and more water resulted in more $\mathrm{N}$ leakage. Additionally, considering the comprehensive benefits for winter wheat, medium fertilizer $\left(\mathrm{N}, 225 \mathrm{~kg} \mathrm{ha}^{-1}\right)$ is an optimal scheme with medium water $\left(3150 \mathrm{~m}^{3} \mathrm{ha}^{-1}\right)$. For summer maize, medium water $\left(1350 \mathrm{~m}^{3} \mathrm{ha}^{-1}\right)$ and high fertilizer $\left(\mathrm{N}, 162 \mathrm{~m}^{3} \mathrm{ha}^{-1}\right)$ were optimal treatment. The above schemes have the best comprehensive benefits for agricultural production in the case area.
\end{abstract}

Keywords: crop yield, groundwater quality, leakage characteristic, $\mathrm{N}$ use efficiency, Weishan Irrigation Region

\section{Introduction}

In agricultural production activities, the problem of excessive application of water and fertilizer exists all

*e-mail: 409538088@chd.edu.cn over the world, and the agroecological environment is destroyed to some extent [1-5]. In particular, the water environment is contaminated severely, which impacts normal production activities [6,7]. Agricultural nonpoint source (NPS) pollution is now the No. 1 pollution source in waterways, with excessive application of water and fertilizer being the single largest contributor. 
Statistically, the world's water bodies $(30-50 \%)$ are contaminated by NPS pollution [8]. Thus, water pollution control is extremely urgent.

Nitrogen $(\mathrm{N})$ is the most important essential element for living organisms on the earth. The utilization of $\mathrm{N}$ fertilizer for cereal production has made prominent contributions to meeting the grain demands of the world with seven billion people [9]. Therefore, the N pollution is one of the main threats to human health and the ecological environment [10-14]. At present, many researchers have carried out relevant research work. Some researchers focus on improving the NUE in order to reduce the $\mathrm{N}$ leaching (e.g., crop rotation patterns, higher splitting frequency of fertilizer $\mathrm{N}$ application, controlled-release $\mathrm{N}$ fertilizer, lower basal $\mathrm{N}$ fertilizer proportion and optimal $\mathrm{N}$ rate based on soil $\mathrm{N}$ test) [15-18]. Nevens et al. indicated that rotation of different fields was one of the main ways to prevent nutrient loss [19]. The TN content in the topsoil under crop rotation has been found to increase by $25 \%$ compared with monocropping [20].

For soil testing and fertilizer recommendation, many researchers have made great advances. The NUE of soil testing and fertilizer recommendation increased by $5.95 \%$ in one study [21], and it increased by $1.89 \%$ in another [22]. These findings show that the planting structure and fertilization method are extremely vital measures to reduce fertilizer loss, especially in intensive crop-growing areas. Excess $\mathrm{N}$ fertilizer can leach through the soil profile, most commonly as nitrate, emerging into surface waters with high mobility [23] and causing agricultural NPS pollution, water eutrophication [24]. $\mathrm{NO}_{3}-\mathrm{N}$ and $\mathrm{NH}_{4}-\mathrm{N}$ accounted for $80-90 \%$ and $0.5-1 \%$, respectively, in runoff loss [25]. $\mathrm{N}$ amount by plant uptake varied among these different crops but with little variation in fertilizer use efficiency [16].

The migration process of $\mathrm{N}$ is very complex, including absorption, fixing, nitrification, and denitrification [26]. Different soil textures, as well as hydrological conditions, have obvious effects on interactions. Reasonable application of water and fertilizer not only enhances NUE, but also increases crop yield. According to previous studies, high, medium, and low fertilizer were applied to the irrigation water volume. For precise quantification, the exact ration of water and fertilizer is rigorously calculated by rotation, soil testing, and optimized fertilizer application.

However, considering crop yield and the coupling of water and fertilizer, studies are rare on groundwater pollution, especially in irrigated agricultural areas. Furthermore, the overall environmental impacts of fertilizer application among different crops have not been evaluated thoroughly and systematically. Taking the Weishan irrigation region as the research area, $\mathrm{N}$ leakage, utilization characteristics, and effects on groundwater combined with local crop yield and reasonable water and fertilizer treatment were studied to explore the leakage characteristics of $\mathrm{N}$ in farmland and the effect on groundwater. The purpose was to seek the optimal solution to prevent groundwater pollution due to excessive watering and fertilization.

\section{Material and Methods}

\section{Study Area}

Located in Dong'e County of Shandong Province $\left(35^{\circ} 47^{\prime}-37^{\circ} 03^{\prime} \mathrm{N}, \quad 115^{\circ} 16^{\prime}-116^{\circ} 30^{\prime} \mathrm{E}\right)$, the Weishan irrigation region is one of the five largest irrigated regions in the downstream of the Yellow River, as shown in Fig.1. Climatologically, the Weishan irrigation region is located in a semi-arid region with a mean annual precipitation of approximately $566.7 \mathrm{~mm}$; nearly $70 \%$ of the total annual rainfall is received between July and September. The main crops are winter wheat and summer maize. Economic crops include vegetable greenhouses and cotton. The experiment was conducted at the Weishan irrigation region test station $\left(36^{\circ} 39^{\prime} \mathrm{N}, 116^{\circ} 14^{\prime} \mathrm{E}\right)$. The irrigation water source is primarily derived from Yellow River (the first canal) and rainfall. The soil is dominated by an alluvial layer, which includes loam, clay, and sandy loam. In the study, the research layer of the experimental station is mainly loam $(0-80 \mathrm{~cm})$ and sandy loam $(80-160 \mathrm{~cm})$. The groundwater depth is between 1 and $3 \mathrm{~m}$. The groundwater is replenished mainly by rainfall, and its hydrochemical type is predominantly $\mathrm{HCO}_{3}^{-}-\mathrm{SO}_{4}{ }^{2-}$. The initial soil solution properties of the plough layer $(0-20 \mathrm{~cm})$ before the experiment began in 2015 were presented in Table 1.

\section{Experimental Design and Statistical Analysis}

\section{Soil-Pit Test Design}

For the study, soil-pit tests were conducted to complete correlative measurements. Experimental pit (bottomed pit) with a $9 \times 3 \times 4$ factorial design was adopted, with nine design levels from 1 to 9 and three replicates. The length and width of each pit were $4 \mathrm{~m} \times 4 \mathrm{~m}$. Moreover, lining walls $300 \mathrm{~cm}$ deep were constructed among the soil pits to avoid mutual influence, and a blank control (CK) was set up in each treatment. The soil depth in the pit was $280 \mathrm{~cm}$, and the pit was equipped with pipes at different depths, directly connecting the seepage fluid of different deep soils. The soil solution was gathered by a soil solution collector (clay head) at different depths $(20,40,80,120$, and $160 \mathrm{~cm})$.

\section{Water and Fertilizer Implementation Plan Design}

The experiment was conducted from October 2015 to July 2016. The type of winter wheat was Tainong 18. For winter wheat, the base fertilizer $\left(\mathrm{N}, 15 \% ; \mathrm{P}_{2} \mathrm{O}_{5}\right.$, $15 \% ; \mathrm{K}_{2} \mathrm{O}, 15 \%$ ) was the same for the nine treatments 


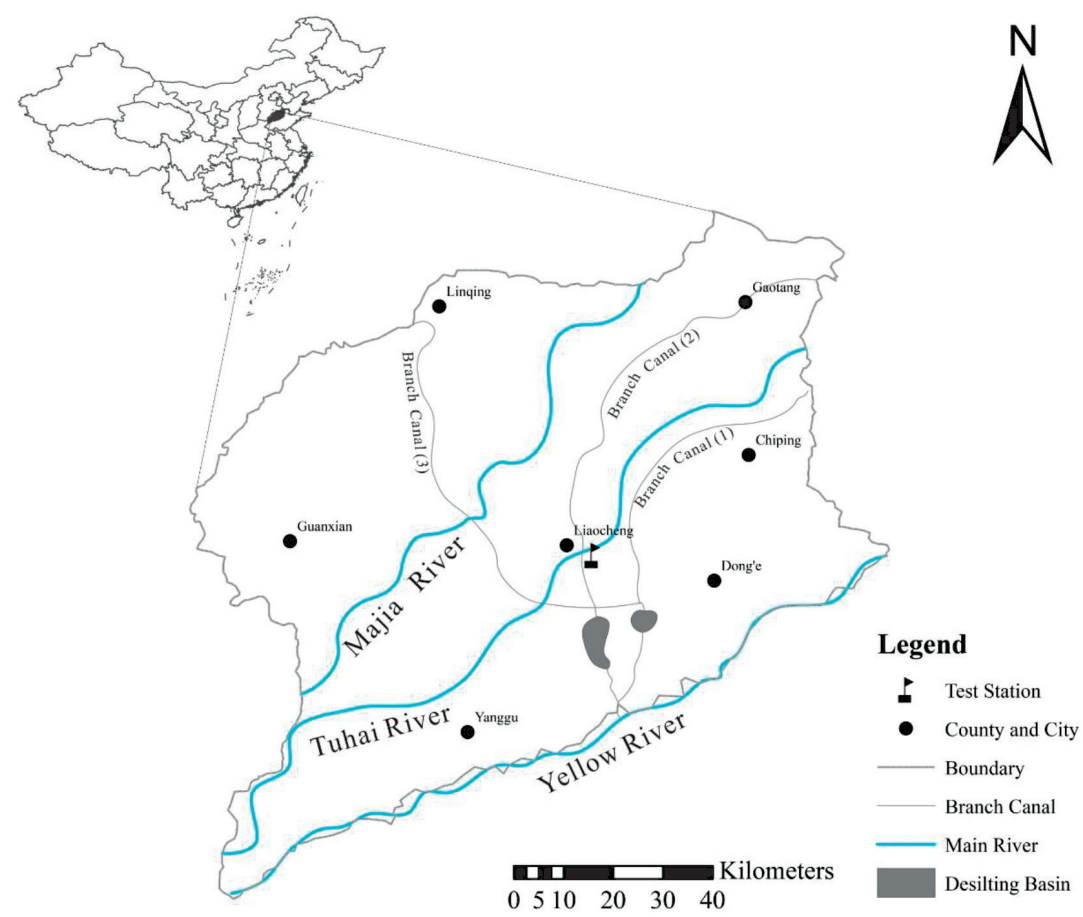

Fig. 1. Location of experiment field site.

Table 1. The initial soil solution properties of plough layer.

\begin{tabular}{|c|c|c|c|c|c|}
\hline $\begin{array}{c}\text { Soil depth } \\
(\mathrm{cm})\end{array}$ & $\begin{array}{c}\mathrm{TN} \\
\left(\mathrm{mg} \mathrm{L}^{-1}\right)\end{array}$ & $\begin{array}{c}\text { Olsen-P } \\
\left(\mathrm{mg} \mathrm{L}^{-1}\right)\end{array}$ & $\begin{array}{c}\text { Olsen-K } \\
\left(\mathrm{mg} \mathrm{L}^{-1}\right)\end{array}$ & $\begin{array}{c}\mathrm{NH}_{4}-\mathrm{N} \\
\left(\mathrm{mg} \mathrm{L}^{-1}\right)\end{array}$ & $\begin{array}{c}\mathrm{NO}_{3}-\mathrm{N} \\
\left(\mathrm{mg} \mathrm{L}^{-1}\right)\end{array}$ \\
\hline $0-20$ & 220 & 12.9 & 103.6 & 5.6 & 150 \\
\hline
\end{tabular}

(1 to 9), and the topdressing was urea (U; N, 46\%). The urea was applied twice, with $1 / 2$ in the elongation stage and $1 / 2$ in the heading stage. $\mathrm{P}$ and $\mathrm{K}$ fertilizers in all treatments were applied at the bottom application dose of $94 \mathrm{~kg} \mathrm{ha}^{-1}$. Three fertilization schemes were used ('low' means below the average of fertilization or irrigation water in actual agricultural production, 'medium' equal to the average of fertilization or irrigation water in actual agricultural production, 'high' means above the average of fertilization or irrigation water in actual agricultural production.): low fertilization treatment $(1,2,3)$, medium fertilization (4, $5,6)$, and high fertilization $(7,8,9)$. Winter wheat was irrigated in the following four stages: overwintering stage (OW, November, 2015 to February, 2016), turning green/elongation stage (TGE, mid-February to midMarch, 2016), heading stage (HD, April to early May, 2016), and grain-filling stage (GF, late May to early June, 2016). In the overwintering stage, the irrigation water was consistent with nine soil-pit treatments, and then three layout levels were designed in the other three stages respectively: pits 1,4 and 7 were high water treatment; pits 2,5 and 8 were medium water treatment; and pits 3, 6 and 9 were low water treatment (Table 2). The seeds were seeded on October 8, 2015 and harvested on June 1, 2016.
For summer maize, the type of seed was Ludan 981, sown immediately after the winter wheat harvest (June 2016). Both bases are compound fertilizers (N, $15 \% ; \mathrm{P}_{2} \mathrm{O}_{5}, 15 \% ; \mathrm{K}_{2} \mathrm{O}, 15 \%$ ), and the topdressing was $\mathrm{U}(\mathrm{N}, 46 \%)$. Half of the fertilizer application was at base application, and the remaining half was in the tasseling stage (July 14 to August 1, 2016). Three levels of fertilization were designed: pits 1,2 and 3 high fertilizer treatment; pits 4,5 and 6 medium fertilizer treatment; and pits 7,8 and 9 low fertilizer treatment. Summer maize was irrigated in the following seeding stage (late June 2016) and tasseling stage (July 21 to August 6, 2016). High water treatment $(1,4,7)$, medium water treatment $(2,5,8)$, and low water treatment $(3$, 6,$9 ; 1080 \mathrm{~m}^{3} \mathrm{ha}^{-1}$ ) were implemented, respectively (Table 3). The seeds were sown on June 2, 2016 and harvested on October 4, 2016.

\section{Sampling and Measurement}

Soil solution samples (27 soil pits) were collected from March 14, 2016 to July 28, 2016. The soil solution was extracted one day after fertigation. In the summer maize growth period, soil solution samples were obtained one day after seeding and tasseling stage fertigation for indoor determination. Each sample 
Table 2. Fertilization and Irrigation Plan of Winter wheat.

\begin{tabular}{|c|c|c|c|c|c|c|c|c|c|}
\hline \multirow{2}{*}{ Treatment } & \multirow{2}{*}{$\begin{array}{l}\text { Schemes } \\
\text { (fertilizer) }\end{array}$} & \multicolumn{3}{|c|}{ Fertilizer inputs $\left(\mathrm{kg} \mathrm{ha}^{-1}\right)$} & \multirow{2}{*}{$\begin{array}{c}\text { Schemes } \\
\text { (water) }\end{array}$} & \multicolumn{4}{|c|}{ Amounts of irrigation $\left(\mathrm{m}^{3} \mathrm{ha}^{-1}\right)$} \\
\hline & & $\mathrm{N}$ & $\mathrm{P}_{2} \mathrm{O}_{5}$ & $\mathrm{~K}_{2} \mathrm{O}$ & & OW & TGE & HD & GF \\
\hline 1 & \multirow{3}{*}{ High } & 300 & 94 & 94 & High & 675 & 1050 & 1050 & 1050 \\
\hline 2 & & 300 & 94 & 94 & Medium & 675 & 825 & 825 & 825 \\
\hline 3 & & 300 & 94 & 94 & Low & 675 & 600 & 600 & 600 \\
\hline 4 & \multirow{3}{*}{ Medium } & 225 & 94 & 94 & High & 675 & 1050 & 1050 & 1050 \\
\hline 5 & & 225 & 94 & 94 & Medium & 675 & 825 & 825 & 825 \\
\hline 6 & & 225 & 94 & 94 & Low & 675 & 600 & 600 & 600 \\
\hline 7 & \multirow{3}{*}{ Low } & 178 & 94 & 94 & High & 675 & 1050 & 1050 & 1050 \\
\hline 8 & & 178 & 94 & 94 & Medium & 675 & 825 & 825 & 825 \\
\hline 9 & & 178 & 94 & 94 & Low & 675 & 600 & 600 & 600 \\
\hline
\end{tabular}

Table3. Fertilization and Irrigation Plan of Summer Maize.

\begin{tabular}{|c|c|c|c|c|c|c|c|}
\hline \multirow{2}{*}{ Treatment } & \multirow{2}{*}{$\begin{array}{c}\text { Schemes } \\
\text { (fertilizer) }\end{array}$} & \multicolumn{3}{|c|}{ Fertilizer inputs $\left(\mathrm{kg} \mathrm{ha}^{-1}\right)$} & \multirow{2}{*}{$\begin{array}{c}\text { Schemes } \\
\text { (water) }\end{array}$} & \multicolumn{2}{|c|}{ Amounts of irrigation $\left(\mathrm{m}^{3} \mathrm{ha}^{-1}\right)$} \\
\hline & & $\mathrm{N}$ & $\mathrm{P}_{2} \mathrm{O}_{5}$ & $\mathrm{~K}_{2} \mathrm{O}$ & & Seeding & Tasseling stage \\
\hline 1 & \multirow{3}{*}{ High } & 162 & 94 & 94 & High & 750 & 750 \\
\hline 2 & & 162 & 94 & 94 & Medium & 675 & 675 \\
\hline 3 & & 162 & 94 & 94 & Low & 540 & 540 \\
\hline 4 & \multirow{3}{*}{ Medium } & 134 & 94 & 94 & High & 750 & 750 \\
\hline 5 & & 134 & 94 & 94 & Medium & 675 & 675 \\
\hline 6 & & 134 & 94 & 94 & Low & 540 & 540 \\
\hline 7 & \multirow{3}{*}{ Low } & 108 & 94 & 94 & High & 750 & 750 \\
\hline 8 & & 108 & 94 & 94 & Medium & 675 & 675 \\
\hline 9 & & 108 & 94 & 94 & Low & 540 & 540 \\
\hline
\end{tabular}

leakage was measured using 10 litre plastic containers, gathered 15 days after each irrigation or rainfall. Moreover, groundwater samples were collected from March 2014 to October 2016 from the 76 groundwater observation wells at intervals of 10-15 days. The contents of TN were accurately gathered with a polyethylene bottle $(50 \mathrm{ml})$, which is the main monitoring index of groundwater quality standard. All the absorbances of the samples (soil solution, groundwater samples, and stem, leaves, and seeds of crops) were scrupulously measured by UV spectrophotometer (UV-2200) and FT-NIR spectrophotometer (IR-960), with professional guidance.

\section{Statistical Analysis}

(1) Calculation of $\mathrm{N}$ and $\mathrm{P}$ use efficiency

The formula to calculate the TN (the total nitrogen) and A-P (available phosphorous) utilization ratio is as follows $[27,28]$ :

$$
M_{N P}=\frac{(A \times a+B \times b)}{A} \times 100
$$

$$
\begin{gathered}
N_{1}=A / 100 \times M_{N P} \\
P=\left(N_{1}-N_{0}\right) / N_{2} \times 100
\end{gathered}
$$

...where $M_{N P}$ is the amount of $\mathrm{N}$ absorbed by crops for $100 \mathrm{~kg}$ economic yield, $\mathrm{kg} ; A$ is Grain yield of crops, $\mathrm{kg} \mathrm{ha}^{-1} ; a$ is Grain N content, \%; $B$ is Stem and leaf yield of crops, $\mathrm{kg} \mathrm{ha}^{-1} ; b$ is Stem and leaf $\mathrm{N}$ content, $\% ; N_{0}$ is $\mathrm{N}$ uptake by blank test crops, $\mathrm{kg} \mathrm{ha}^{-1} ; N_{1}$ is Total amount of $\mathrm{N}$ in soil, $\mathrm{kg} \mathrm{ha}^{-1} ; N_{2}$ is the total amount of $\mathrm{N}$ fertilizer application in test pit, $\mathrm{kg} \mathrm{ha}^{-1} ; P$ is NUE, $\%$.

(2) Calculation of TN or A-P leakage

The formula to calculate TN or A-P leakage is as follows [29]:

$$
L=C \times V_{S} / 100
$$

...where $L$ is the leaching amount, $\mathrm{kg} \mathrm{ha}^{-1} ; C$ is the TN or A-P concentration, $\mathrm{mg} \mathrm{L}^{-1} ; V_{S}$ is the sum of leaching volume, $\mathrm{ml}$. 


\section{Results}

The Characteristics of TN Leakage in Soil Solution Treated with Different Water and Fertilizer

The variation of TN concentration was fairly obvious in the crops' growth period in different soil layers, as identified in Fig.2. The TN concentration of the shallow layer $(0-40 \mathrm{~cm})$ was significantly higher than that in the lower soil $(80-160 \mathrm{~cm})$ in the pre-stage of the growth period. Subsequently, the TN concentration of the lower soil gradually increased until harvest time. Under high water irrigation, the $\mathrm{TN}$ accumulation concentration of the lower soil layer increased more rapidly than the low irrigation. The TN concentration of the shallow soil layer was steady to some extent, with an average of $292.68 \mathrm{mg} \mathrm{L}^{-1}$, and there was no obvious distinction between different treatments, with a balance range of 263.12-310.46 $\mathrm{mg} \mathrm{L}^{-1}$. The $\mathrm{TN}$ concentration of $0-20 \mathrm{~cm}$ declined gradually in the heading stage, with a minimum of $260.1 \mathrm{mg} \mathrm{L}^{-1}$, and then rose to within the balance range. Comparatively speaking, a smooth trend of $20-40 \mathrm{~cm}$ was similar to $0-20 \mathrm{~cm}$ in the middle and late stages of crop growth. After the heading stage, the accumulation effect of the TN concentration was more significant at $120-160 \mathrm{~cm}$, especially under high water condition. However, the TN concentration of all treatments was significantly decreased at $0-20 \mathrm{~cm}$ between the heading stage and the filling stage of winter wheat. Above that, the aggregation layer of the TN concentration was affected by different treatments, and the main influencing factor was dominated by irrigation levels. Noticeably, for summer maize, the TN concentration of the lower soil layer was significantly higher than that of winter wheat, and mainly concentrated at $120-160 \mathrm{~cm}$.

The distribution characteristics of TN concentration in the soil profile were obvious in the different growth stages of crops. Between the turning green and elongation stages (winter wheat), the TN concentration was mainly concentrated at $20-40 \mathrm{~cm}$, with an average of $304.43 \mathrm{mg} \mathrm{L}^{-1}$, and other soil layers at $0-20 \mathrm{~cm}$ (280.93 $\left.\mathrm{mg} \mathrm{L}^{-1}\right), 40-80 \mathrm{~cm}^{-1}\left(265.3 \mathrm{mg} \mathrm{L}^{-1}\right), 80-120 \mathrm{~cm}$ (214.35 mg L-1), and $120-160 \mathrm{~cm}\left(189.17 \mathrm{mg} \mathrm{L}^{-1}\right)$. In the heading stage, the TN concentration was accumulated in the soil layer $\left(40-80 \mathrm{~cm}\right.$, average $\left.332.68 \mathrm{mg} \mathrm{L}^{-1}\right)$, and the TN concentration was increased more apparently in the lower soil layer, under high water and fertilizer (treatment 1). Although the trend above was similar to all treatments, the TN concentration of low water and fertilizer (treatment 9) at 120-160 cm was less obvious than medium-high water. In the filling stage, the soil a)

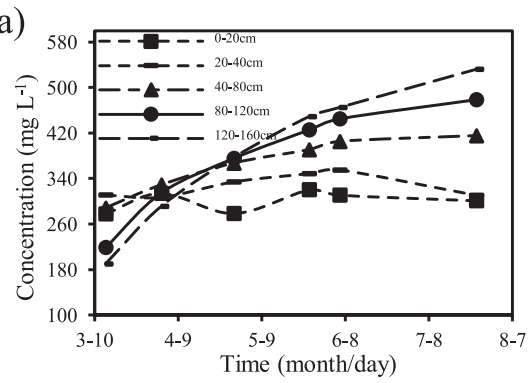

d)

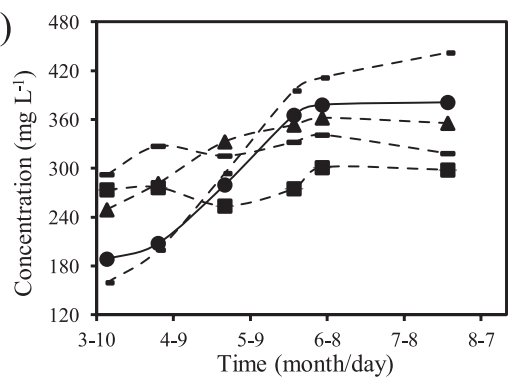

g)

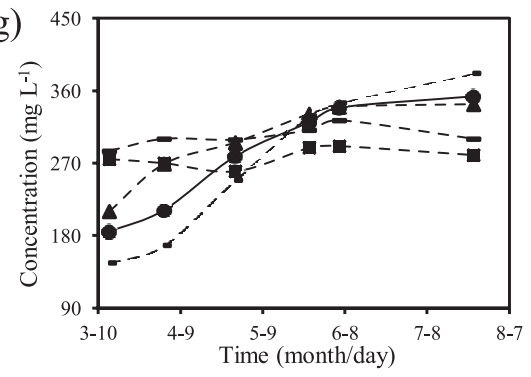

b)

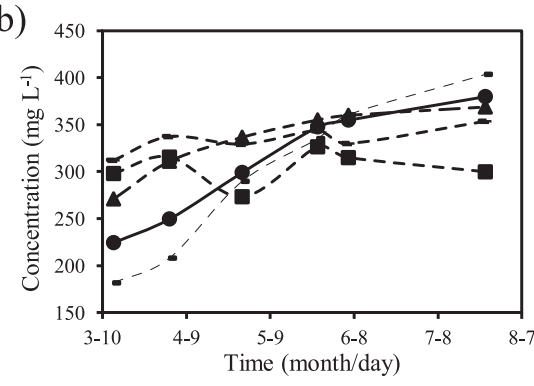

e)

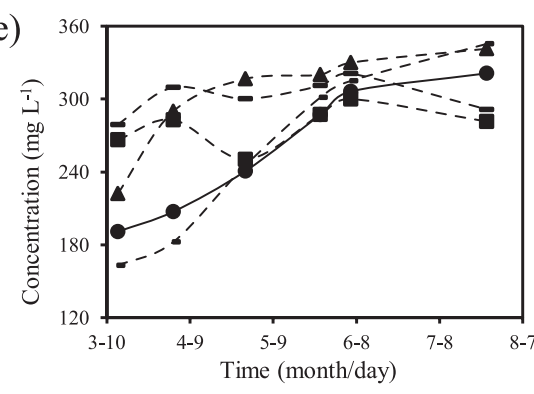

h)

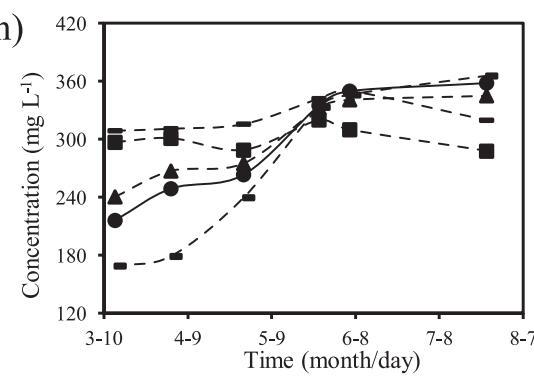

c)

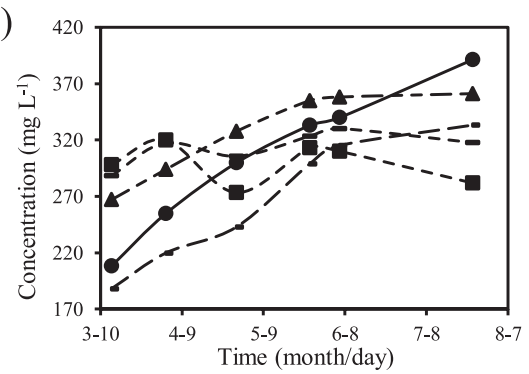

f)

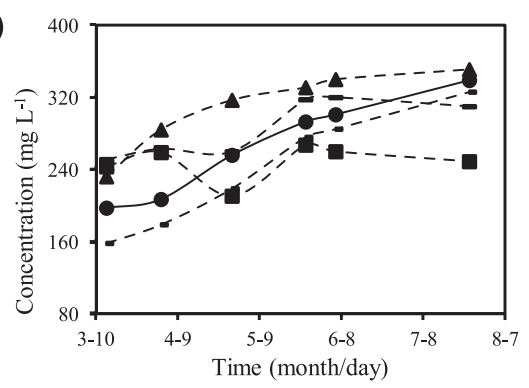

i)

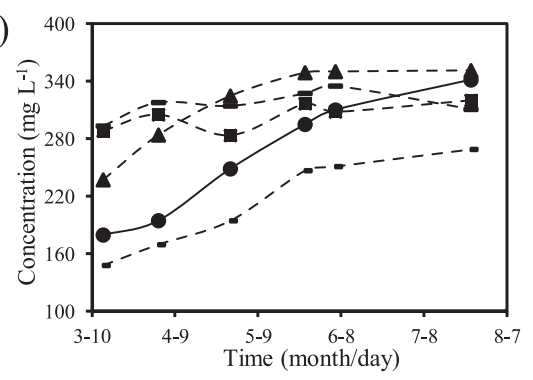

Fig. 2. TN concentration distribution in different treatments.

above Charts: a, b, c, d, e, f, g, h, i represents treatments $1,2,3,4,5,6,7,8,9$ respectively. 

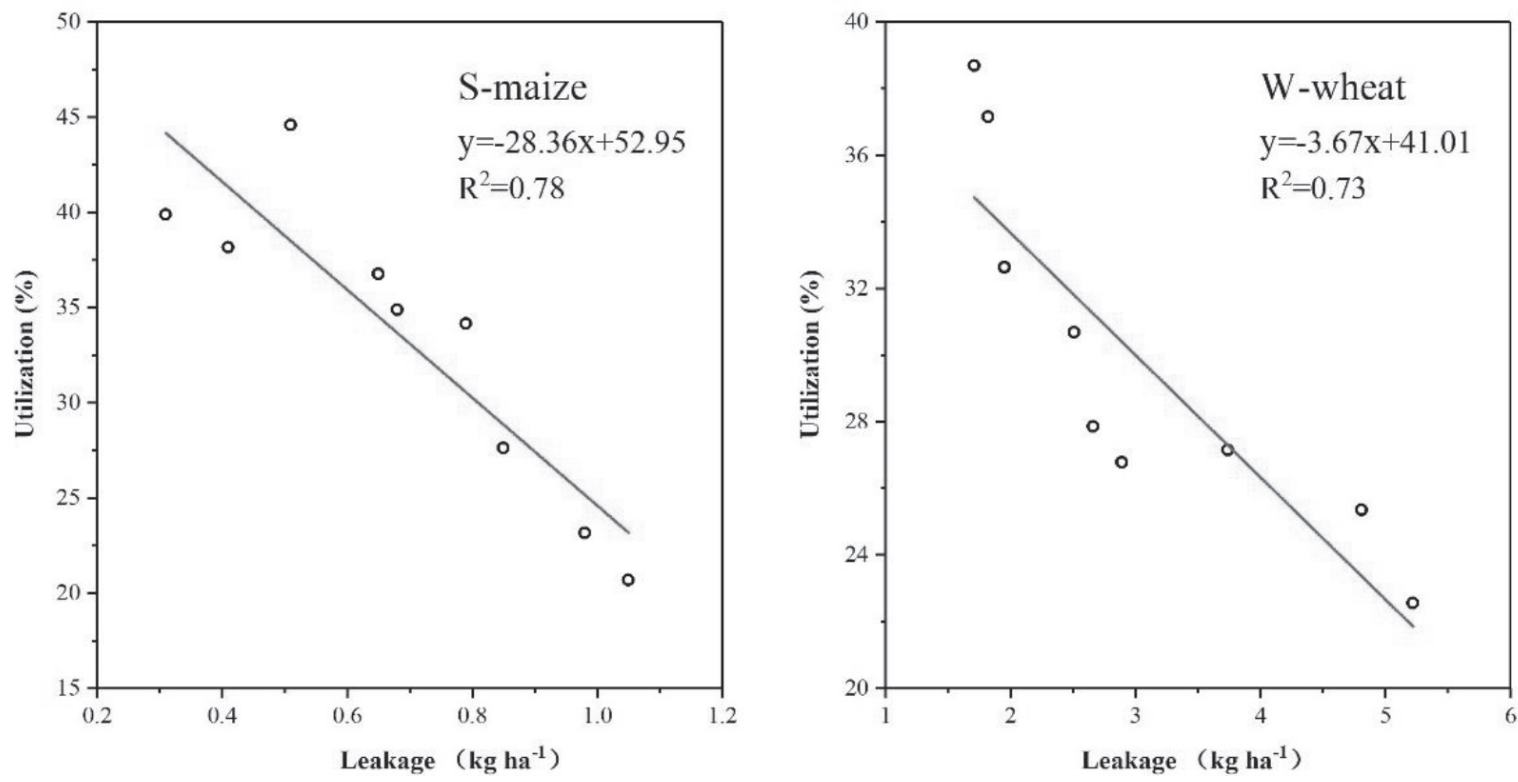

Fig. 3. The correlation between the $\mathrm{N}$ utilization and fertilization leakage.

Table 4. NUE by W-wheat and S-maize, Grain yield, total leakage during the 2014 and 2015 crop growing seasons.

\begin{tabular}{|c|c|c|c|c|}
\hline $\begin{array}{c}\text { Crop } \\
\text { species }\end{array}$ & Treatment & $\begin{array}{l}\text { NUE } \\
(\%)\end{array}$ & $\begin{array}{c}\text { Yield } \\
\left(\mathrm{kg} \mathrm{ha}^{-1}\right)\end{array}$ & $\begin{array}{l}\text { TN leakage } \\
\left(\mathrm{kg} \mathrm{ha}^{-1}\right)\end{array}$ \\
\hline \multirow{10}{*}{ W-wheat } & $\mathrm{CK}$ & - & 4709.13 & - \\
\hline & 1 & $22.50 \mathrm{de}$ & $6300.51 \mathrm{c}$ & $5.22 \mathrm{a}$ \\
\hline & 2 & $37.15 \mathrm{a}$ & $6610.21 \mathrm{~b}$ & $3.74 \mathrm{ab}$ \\
\hline & 3 & $24.69 \mathrm{cde}$ & $5861.36 \mathrm{e}$ & $2.51 \mathrm{bcd}$ \\
\hline & 4 & $33.35 b$ & $6173.00 \mathrm{~cd}$ & $4.81 \mathrm{a}$ \\
\hline & 5 & $38.69 \mathrm{a}$ & $7000.25 \mathrm{a}$ & $1.91 \mathrm{~cd}$ \\
\hline & 6 & $24.94 \mathrm{~cd}$ & $5855.55 \mathrm{e}$ & $1.82 \mathrm{f}$ \\
\hline & 7 & $27.78 \mathrm{c}$ & 5877.32 de & $2.89 \mathrm{bc}$ \\
\hline & 8 & $27.86 c$ & 5996.50de & $2.66 \mathrm{bcd}$ \\
\hline & 9 & $20.63 \mathrm{e}$ & $4991.05 f$ & $1.61 \mathrm{f}$ \\
\hline \multirow{10}{*}{ S-maize } & $\mathrm{CK}$ & - & 4954.04 & \\
\hline & 1 & $34.69 \mathrm{~d}$ & $8600.11 \mathrm{~cd}$ & $1.05 \mathrm{a}$ \\
\hline & 2 & $40.63 \mathrm{a}$ & $9750.51 \mathrm{a}$ & $0.85 b c$ \\
\hline & 3 & $34.15 \mathrm{~d}$ & $7985.35 \mathrm{e}$ & $0.79 \mathrm{c}$ \\
\hline & 4 & $38.78 \mathrm{~b}$ & $9150.21 \mathrm{~b}$ & $0.57 \mathrm{de}$ \\
\hline & 5 & $36.75 c$ & $8750.01 \mathrm{c}$ & $0.65 \mathrm{~d}$ \\
\hline & 6 & $34.89 \mathrm{~d}$ & $8425.67 d$ & $0.68 \mathrm{~d}$ \\
\hline & 7 & $33.15 \mathrm{~d}$ & $7889.12 \mathrm{e}$ & $0.98 b$ \\
\hline & 8 & $30.16 \mathrm{e}$ & $7500.17 f$ & $0.51 \mathrm{e}$ \\
\hline & 9 & $28.89 \mathrm{e}$ & $5350.05 f$ & $0.41 \mathrm{f}$ \\
\hline
\end{tabular}

The CK represents blank control, the letters (a, b, c, d, e, f) represent significant difference $(\mathrm{p}<0.05)$. Different letters indicate significant differences, the same letter means the difference is not significant. depth at 40-80 $\mathrm{cm}$ showed an accumulation layer for treatments 3,6 , and 9 , with the TN concentration reaching an average of $327 \mathrm{mg} \mathrm{L}^{-1}$. Accumulation was noticed in the bottom soil $(120-160 \mathrm{~cm})$ for treatments 1,4 , and 7 , reaching an average of $390.67 \mathrm{mg} \mathrm{L}^{-1}$. Other treatments $(2,5,8)$ were concentrated at $80-120 \mathrm{~cm}$, with a mean of $360.05 \mathrm{mg} \mathrm{L}^{-1}$. For summer maize, from the seeding to tasseling stage, the TN concentration was distinctly higher than that for winter wheat in the lower soil layer (80-160 cm). Particularly in the tasseling stage, the $\mathrm{TN}$ concentration was accumulated at $120-160 \mathrm{~cm}$, and treatment 1 was typical, with the peak value of $532.12 \mathrm{mg} \mathrm{L}^{-1}$.

\section{TN Leakage During Crop Growth Period}

$\mathrm{N}$ leakage was an important factor causing groundwater source pollution, and the $\mathrm{N}$ leakage calculated accurately was the key to the analysis of the regional agricultural source pollution. In the whole experimental period, there were a total of nine rainfalls. The minimum rainfall recorded was only $0.5 \mathrm{~mm} \mathrm{~d}^{-1}$, and the maximum rainfall was $40.5 \mathrm{~mm} \mathrm{~d}^{-1}$. The designed irrigation amount was $67.5 \mathrm{~mm}$. The TN leakage of winter wheat in the turning green-jointing stage was larger than that of other periods, up to the peak of leakage in the period, gradually declining after that with the lowest leakage. Compared with winter wheat, the leakage of summer maize during the jointing stage and silking stage was larger than others. As shown in Table 4, the leakage of the winter wheat test was more than that of summer maize. Under high water and fertilizer treatment, winter wheat and summer maize (treatment 1) leakage were larger, reaching $5.22 \mathrm{~kg} \mathrm{ha}^{-1}$ and $1.05 \mathrm{~kg} \mathrm{ha}^{-1}$, respectively. In contrast, treatments 5 and 2 were the higher yield and 
utilization rate, but the leakage only was $1.91 \mathrm{~kg} \mathrm{ha}^{-1}$ and $0.85 \mathrm{~kg} \mathrm{ha}^{-1}$. Thus, $\mathrm{N}$ elements were not beneficially absorbed under high water and fertilizer treatment, posing a risk of groundwater pollution. In addition, there was a significant negative correlation between the TN leakage and the N utilization (Fig. 3). These results suggested that high water and high fertilizer were not conducive to $\mathrm{N}$ absorption.

\section{Effects of Different Processing Interactions}

The aim of this experiment was to improve the $\mathrm{N}$ utilization rate in order to ensure improvement of the groundwater environment and to respond to green agriculture. In this section, SPSS statistical software was used in $\mathrm{p}<0.05$ (LSD). The use efficiency of $\mathrm{N}$ and crop yield was noticeably affected by different water and fertilizer treatments (Fig. 4). The TN leakage quantity ranged from 2.02 to $6.27 \mathrm{~kg} \mathrm{ha}^{-1} \mathrm{a}^{-1}$ in the study period (Table 4). The higher leakage was demonstrated in the high water and fertilization treatment, along with the severe pollution risk of underground water. Furthermore, the effect of irrigation water quantity was more significant on the $\mathrm{N}$ leakage in crops (winter wheat - summer maize). For treatments $(1,4,7)$, the average leakage was $5.13 \mathrm{~kg} \mathrm{ha}^{-1}$, and medium water treatments $(2,5,8)$ indicated an average of $3.44 \mathrm{~kg} \mathrm{ha}^{-1}$. The minimum average was $2.61 \mathrm{~kg} \mathrm{ha}^{-1}$ for water treatments $(3,6,9)$. For the crop yields, with the same fertilizer application, the following yields were shown: medium water $>$ high water $>$ low water. However, with the same water application, the yield of high fertilizer was similar to medium fertilizer treatment. The effect of fertilizer application was more significant than water between high fertilizer and low fertilizer. For the high fertilizer treatments $(1,2,3)$, winter wheat and summer maize average yield were respective of $6257.36 \mathrm{~kg} \mathrm{ha}^{-1}$ and $8778.33 \mathrm{~kg} \mathrm{ha}^{-1}$, and medium fertilizer treatments $(4,5,6)$ were $6342.93 \mathrm{~kg} \mathrm{ha}^{-1}$ and $8775.21 \mathrm{~kg} \mathrm{ha}^{-1}$. Low fertilizer treatment $(7,8,9)$ were $5569.32 \mathrm{~kg} \mathrm{ha}^{-1}$ and $6913.05 \mathrm{~kg} \mathrm{ha}^{-1}$. The $\mathrm{N}$ contents in the stem, leaf, and grain from winter wheat and summer maize are shown in Table 5 for calculating NUE. For summer maize, the NUE and yield were highest in treatment $2\left(40.63 \%\right.$ and $9750.51 \mathrm{~kg} \mathrm{ha}^{-1}$, respectively) with leakage $\left(0.85 \mathrm{~kg} \mathrm{ha}^{-1}\right)$. On the contrary, treatment 9 was lowest $\left(28.89 \%\right.$ and $5350.05 \mathrm{~kg} \mathrm{ha}^{-1}$, respectively) with

Table 5. N, P content in stem-leaf and grain from W-wheat and S-maize.

\begin{tabular}{|c|c|c|c|c|}
\hline \multirow{2}{*}{$\begin{array}{c}\text { Crop Spe- } \\
\text { cies }\end{array}$} & \multicolumn{4}{|c|}{ Nutrient Content (\%) } \\
\cline { 2 - 5 } & $\mathrm{N}$ & $\mathrm{P}$ & $\mathrm{N}$ & $\mathrm{P}$ \\
\hline W-wheat & 0.564 & 0.067 & 2.140 & 0.370 \\
\hline S-maize & 0.748 & 0.408 & 1.466 & 0.317 \\
\hline
\end{tabular}

leakage $\left(0.41 \mathrm{~kg} \mathrm{ha}^{-1}\right)$. The effect of water was more obvious than fertilizer on yield for summer maize (high water $>$ medium water $>$ low water overall). The leakage was highest in high water and fertilizer treatment 1 for application to winter wheat.

For winter wheat, NUE and yield were the highest (38.69\% and $7000.25 \mathrm{~kg} \mathrm{ha}^{-1}$, respectively) in treatment 5 , significantly different from other treatments, with low leakage (1.91 kg ha-1). However, low water and fertilizer treatment 9 was opposite to the medium water and fertilizer treatment, with the lowest use efficiency, yield, and leakage $\left(20.63 \%, 4991.05 \mathrm{~kg} \mathrm{ha}^{-1}\right.$, and $1.61 \mathrm{~kg} \mathrm{ha}^{-1}$, respectively). Additionally, for high water and fertilizer treatment 1 , the NUE was similar to treatment 9 at $22.50 \%$, and the yield was $6300.51 \mathrm{~kg} \mathrm{ha}^{-1}$, but the leakage was the highest $\left(5.22 \mathrm{~kg} \mathrm{ha}^{-1}\right)$, approximately triple that of treatment 5. According to the above research results, considering the local economy and environmental protection, treatment 5 was the optimum coupling of water and fertilizer for winter wheat, and treatment 2 was the optimum for summer maize to improve the NUE, reduce the risk of groundwater pollution, and in Fig. 4.

In the last three years, the groundwater $\mathrm{NO}_{3}-\mathrm{N}$ content was increasing in the study area, while the $\mathrm{NH}_{4}-\mathrm{N}$ fluctuation was imperceptible, only with a significant increase in the heading stage and grain filling stage (winter wheat) (Fig. 5). The average annual variation trend of $\mathrm{TN}$ was similar to that of $\mathrm{NO}_{3}-\mathrm{N}$, and the content increased by nearly three times
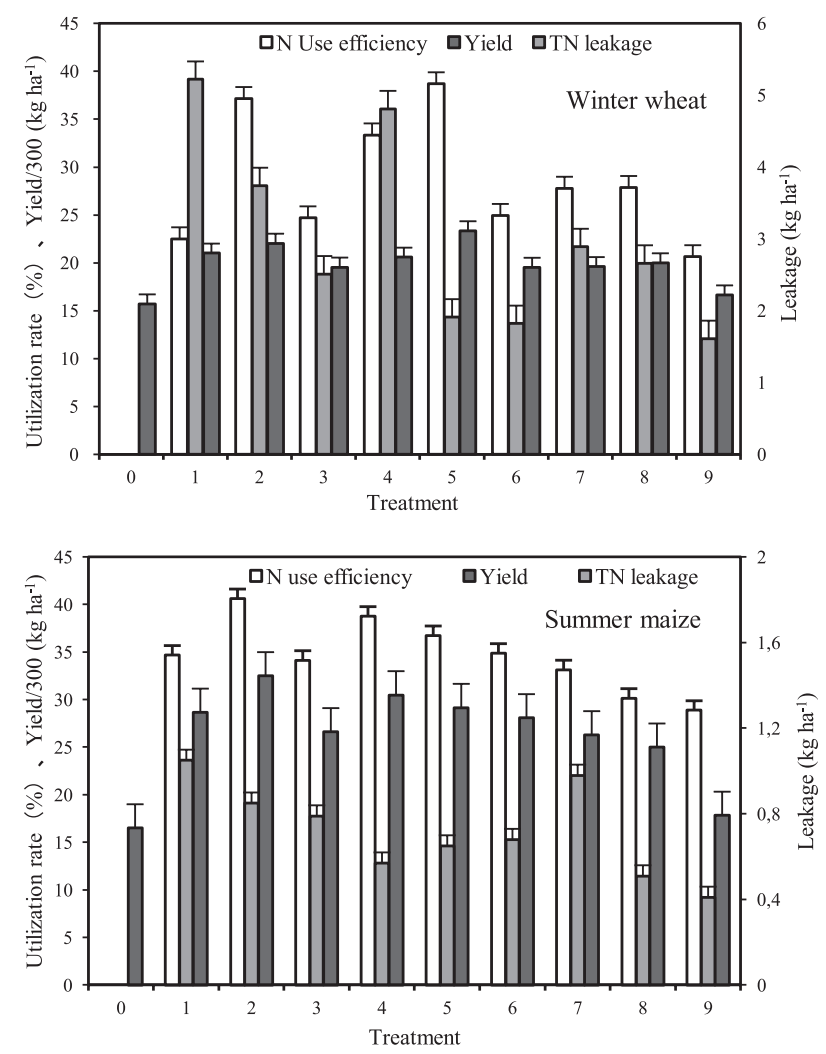

Fig. 4. The relationship between the use efficiency and yield. 


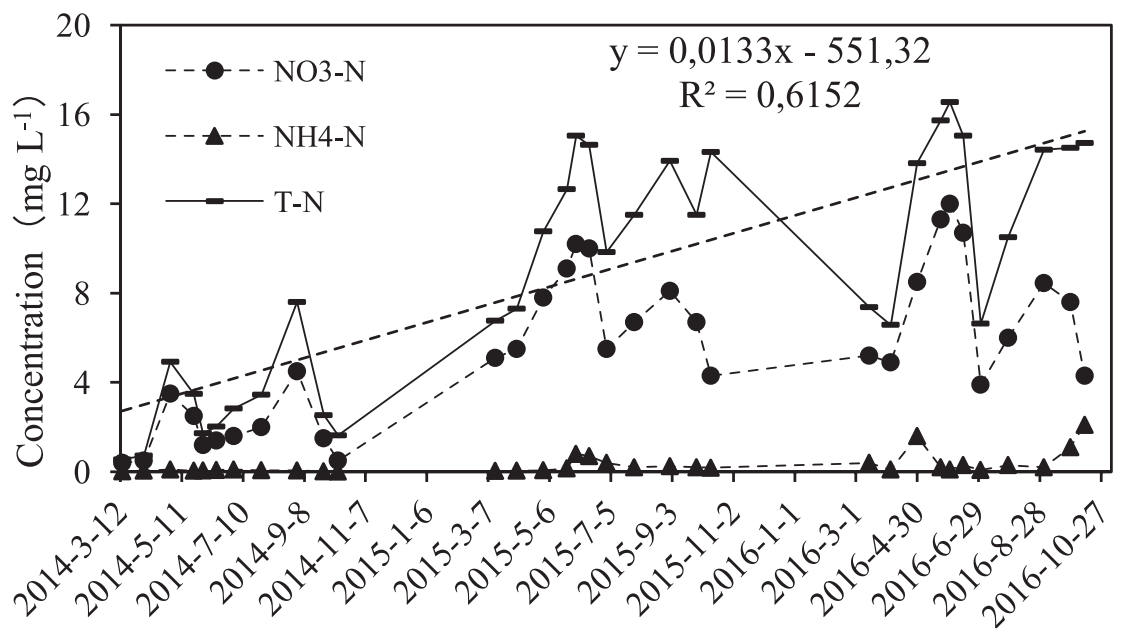

Fig. 5. Variability of $\mathrm{N}$ content in groundwater.

(TN, $13.82 \mathrm{mg} \mathrm{\textrm {L } ^ { - 1 }}$ ), with a determination coefficient of 0.6152 . The nitrate content in the groundwater quality added up to nearly 4.23 times. According to the groundwater quality standard [30], the groundwater belonged to category III $\left(\mathrm{NO}_{3}-\mathrm{N}, 4-12 \mathrm{mg} \mathrm{L}^{-1}\right)$. The maximum limit of the underground water source for drinking water standard was almost approached $\left(\leq 20 \mathrm{mg} \mathrm{L}^{-1}\right)$ and continuously deteriorated, which should arouse concern and prompt appropriate measures to further improve the groundwater environment. Based on annual average rainfall records of the Liaocheng hydrographic office in recent years, $\mathrm{N}$ seepage has been concentrated in the irrigation and rainfall period.

\section{Discussion}

Effects of Different Water-Fertilizer Treatments on TN Leakage Characteristics in The Soil Profile

The TN leakage characteristics in farmland were affected by the irrigation quantity, rainfall, rainfall intensity, soil characteristics and land use mode, planting structure, agricultural activities, and so on [31]. The leakage occurred when fertilizer used exceeded crop demand. Furthermore, the environment might be damaged through migration and denitrification [32]. In this experiment, fertilizer and irrigation quantities were an important factor influencing distributing characteristics (TN), with apparent variation of 80-160 cm, which was an accumulative effect. The TN content of $80-160 \mathrm{~cm}$ gradually increased in the crop growth period with the $\mathrm{N}$ element infiltrating, and the $\mathrm{NO}_{3}-\mathrm{N}$ was the main ingredient contributing to infiltration, which was easily dissolved and strong mobility. However, the TN content of $0-40 \mathrm{~cm}$ was more directly affected by irrigation water with wash action than 120-160 cm, which had inconspicuous fluctuation. The measure, integration of water and fertilizer, prompted the $\mathrm{N}$ element to transfer faster from the surface to the bottom of the studied soil layer, indirectly contributing to the balance of $\mathrm{N}$ at $0-40 \mathrm{~cm}$ without much peak or valley value. Above that, eventually, the study indicated that the TN content was accumulated at 120-160 $\mathrm{cm}$, accelerating the pollution of underground water. Compared with previous studies, the study results still have some differences which may be caused by nature factors (precipitation, temperature, climate, etc.) [33] or human factors (experiment operation, standard, etc.).

\section{Effects of Different Water and Fertilizer Treatments on TN Leakage}

According to the study, the different TN leakages occurred under a certain amount of water (precipitation, irrigation) in the field. The leakage can be strengthened in a high irrigation amount: The leakage of treatment 1 with high water was the greatest (TN, $6.27 \mathrm{~kg} \mathrm{ha}^{-1}$ ) during the whole experiment, and treatment 9 with low water was the least $\left(\mathrm{N}, 2.01 \mathrm{~kg} \mathrm{ha}^{-1}\right)$, infiltrating into groundwater and resulting in groundwater pollution [34]. In addition, when the rainfall intensity exceeded the infiltration rate of the local soil, surface runoff would be generated, and then the accumulated $\mathrm{N}$ in the soil surface entered the surface water body, causing surface water body pollution (lake, rivers, ditches, etc.). The groundwater investigation based on outdoor test also indicated that an increasing trend of groundwater $\mathrm{NO}_{3}-\mathrm{N}$ and $\mathrm{TN}$ content was clearly observed during recent years, referring to a vital indicator of groundwater quality. Tang et al. argued that the groundwater quality deteriorated year by year in the Weishan irrigation region [35]. In the past 10 years, the growth rate of agricultural fertilizer application was approximately $23 \%$ [36]. Combining with the groundwater $\mathrm{NO}_{3}-\mathrm{N}$ and $\mathrm{TN}$ content increasing trend, the increase of fertilizer application actually contributed to the groundwater pollution, which was consistent with previous research conclusions. At present, flooding irrigation methods 
$\left(3600-4500 \mathrm{~m}^{3} \mathrm{ha}^{-1}\right)$ are still applied in the study area, resulting in low groundwater depth (1.5-3 m) and enhanced soil leaching, which leads to high content of $\mathrm{NO}_{3}-\mathrm{N}$ in shallow groundwater. Excessive water and fertilizer were widespread in the main grain area of the north China plain (southwest of Shandong, northwest, etc.). Excessive application of $\mathrm{N}$ fertilizer had been identified as a major source of groundwater pollution [37]. Hence, optimizing the combination of water and fertilizer is an important measure to solve $\mathrm{N}$ pollution, suggesting water and fertilizer optimum management has a significant effect on improving groundwater quality.

\section{Effect of Different Water and Fertilizer Treatments on N Utilization}

The NUE was obviously distinct between different water and fertilizer treatments $(p<0.05)$. Treatment 5 for winter wheat was optimal $(\mathrm{N}, 38.69 \%)$, with medium water and fertilizer. For summer maize, treatment 2 was optimal (N, 40.63\%), with high fertilizer and medium water. Other researchers have come to similar conclusions. For instance, Chen et al. found that the use efficiency of $\mathrm{N}$ was $52.4 \%$ after medium fertilizer treatment [38]. Compared with conventional water and fertilizer application, the use efficiency for $\mathrm{N}$ increased by $10.19 \%$ for winter wheat and $7.29 \%$ for summer maize. Based on the approximate amounts of $\mathrm{N}$ fertilizer application, the growth rate was slightly higher than that previously reported for the soil testing formula experiment [39]. One possible reason may be different measurement methods. As noted above, in agricultural production, the optimization of water and fertilizer was a key measure to improve the use efficiency of water and fertilizer and to decrease water body pollution. Compared with other research results, the optimization effect in this study is different, and the causes might be the differences on crop strains, regional climate, the experiment site (in situ experiment), or treatment standards.

\section{Groundwater Quality}

Protecting the groundwater quality is one of this study's purposes, and the $\mathrm{NO}_{3}-\mathrm{N}$ was uppermost contributor. The main factor causing groundwater pollution is fertilizer application in agricultural activities [40], and excessive application of $\mathrm{N}$ fertilizer has been identified as a major source of groundwater pollution [37]. In Fig. 4, the $\mathrm{TN}\left(\mathrm{NO}_{3}-\mathrm{N}, \mathrm{NH}_{4}-\mathrm{N}\right)$ content is increasing, illustrating the groundwater quality's deterioration in the case. For this reason, unreasonable application of water and fertilizer adopted by local farmers is a critical factor, and excessive application of water and fertilizer was widely popular, as it was deeply rooted in local ideology. In this paper, excessive application of water and fertilizer resulted in more $\mathrm{N}$ accumulating in the bottom soil layer, causing vast quantities of $\mathrm{N}$ in groundwater and, consequently, groundwater pollution.

In the Weishan irrigation region, the content of $\mathrm{NO}_{3}-\mathrm{N}$ in shallow groundwater had been studied by many researchers. The results showed that the $\mathrm{N}$ content in the shallow groundwater was higher than that of the national primary drinking water standard, except for deep groundwater [41]. Shallow groundwater would be severely contaminated with long-term unreasonable water-fertilizer application [42]. The trend of groundwater quality in recent years is consistent with the previous research conclusions, and the conclusions provided a scientific basis for local control of the groundwater environment.

Reasonable application of water and fertilizer played an important role in protecting the groundwater environment. Generally, the irrigation water and fertilizer application quantities are at an average of approximately $4050 \mathrm{~m}^{3} \mathrm{ha}^{-1}$ and $\mathrm{N}, 325 \mathrm{~kg} \mathrm{ha}^{-1}$, respectively, which are greater than the design values. Therefore, the TN leakage in the study area may be more serious. In this study, the conclusion provided a scientific basis for local control of the groundwater environment. Local authorities should develop countermeasures to keep the situation in check as early as possible.

\section{Conclusions}

To study the deteriorating groundwater in the Weishan irrigation region, pit tests of nine treatments were carried out in the Weishan irrigation region station. Results showed that (1) the TN leakage characteristics were significant in different water-fertilizer treatments, and high water caused more $\mathrm{N}$ element accumulation at 120-160 cm, becoming more apparent over time; however, TN content fluctuation of the upper layer was not evident. (2) Medium water-fertilizer application $\left(\mathrm{N}, 225 \mathrm{~kg} \mathrm{ha}^{-1}, 3150 \mathrm{~m}^{3} \mathrm{ha}^{-1}\right.$ ) for winter wheat as well as high fertilizer and medium water treatment (N, $162 \mathrm{~kg} \mathrm{ha}^{-1}, 1350 \mathrm{~m}^{3} \mathrm{ha}^{-1}$ ) for summer maize were optimal schemes to maintain balance between farmers' income and environmental protection; excessive application of water and fertilizer resulted in significant quantities of $\mathrm{N}$ elements in groundwater, causing water pollution. (3) A higher fertilizer used more than $\mathrm{N}$, $225 \mathrm{~kg} \mathrm{ha}^{-1}$ was the main cause of local groundwater quality deterioration in recent years (III groundwater quality), which would possibly pose a greater threat to the local eco-hydrological environment.

There are still many defects in the process of applying water and fertilizer. For instance, the design levels of water and fertilizer and the number of samples need to increase in order to be more persuasive. The optimal coupling of water and fertilizer may vary in different regions, and leakage experiments can be carried out in different temperature zones (South China, Northwest China, etc.). In future studies, $\mathrm{P}$ can be taken 
into account as another major element causing NPS pollution.

\section{Acknowledgment}

This work was supported by "111" Intellect Importation Project (B08039), the key research and development project of Shaanxi Province (2019SF237), the Fundamental Research Funds for the Central Universities (300102299206), the Fundamental Research Funds for the Central Universities, CHD (300102290105), National Natural Science Foundation of China (41877179) and China Postdoctoral Science Foundation (2018M633438).

\section{Conflict of Interest}

The authors declare no conflict of interest.

\section{References}

1. GALLOWAY J.N., TOWNSEND A.R., ERISMAN J.W. Transformation of the nitrogen cycle: recent trends, questions, and potential solutions. Science. 320, 889, 2008.

2. GU B.J., JU X.T., CHANG J. Integrated reactive nitrogen budgets and future trends in China. Proc. Natl. Acad. Sci. USA. 112, 8792, 2015.

3. XIE H., DONG J.W., SHEN Z.Y. Intra- and inter-event characteristics and controlling factors of agricultural nonpoint source pollution under different types of rainfallrunoff events. Catena. 182, 104, 2019.

4. ZENG M., DE V.W., BONTEN L.T. Model-based analysis of the long-term effects of fertilization management on cropland soil acidification. Environ. Sci. Technol. 51, 3843, 2017.

5. ZUO L., ZHANG Z., CARLSON K.M. Progress towards sustainable intensification in China challenged by land-use change. Nat. Sustain. 1, 304, 2018.

6. PAN J., LIU Y., ZHONG X. Grain yield, water productivity and nitrogen use efficiency of rice under different water management and fertilizer-N inputs in South China. Agric. Water Manage. 184, 191, 2017.

7. WANG M., WANG L., CUI Z. Closing the yield gap and achieving high $\mathrm{N}$ use efficiency and low apparent $\mathrm{N}$ losses. Field Crops Res. 209, 39, 2017.

8. MA C.B. Development trend and prospect of agricultural fertilizer application in China. China Agricultural Technology Extension. 6, 6-10, 2016.

9. ZHANG Y., WANG H., LEI Q. Optimizing the nitrogen application rate for maize and wheat based on yield and environment on the Northern China Plain. Sci. Total Environ. 618, 1173, 2018.

10. BRIAN M.D., DANIEL P. 2008. Agricultural nonpoint source water pollution policy: The case of California's Central Coast. Agric. Ecosyst. Environ. 128, 151, 2008.

11. CHEN X., CUI Z., FAN M. Producing more grain with lower environmental costs. Nature. 514, 486, 2014.

12. MABAYA G., UNAMI K., FUJIHARA M. Stochastic optimal control of agrochemical pollutant loads in reservoirs for irrigation. J. Clean Prod. 146, 37, 2017.
13. STROKAL M., YANG H., ZHANG Y. Increasing eutrophication in the coastal seas of China from 1970 to 2050. Mar. Pollut. Bull. 85, 123, 2014.

14. ZHOU M., ZHU B., WANG S. Stimulation of $\mathrm{N}_{2} \mathrm{O}$ emission by manure application to agricultural soils may largely offset carbon benefits: a global meta-analysis. Glob. Change Biol. 23, 4068, 2017.

15. ISLAM S.M., GAIHRE Y.K., BISWAS J.C. Different nitrogen rates and methods of application for dry season rice cultivation with alternate wetting and drying irrigation: fate of nitrogen and grain yield. Agric. Water Manage. 196, 144, 2018.

16. LI W.C., GUO S.F., LIU H.B. Comprehensive environmental impacts of fertilizer application vary among different crops: Implications for the adjustment of agricultural structure aimed to reduce fertilizer use. Agricultural Water Management. 210, 1, 2018.

17. MUSCHIETTI P., MD P., CIPRIOTTI P.A. Using sitespecific nitrogen management in rainfed corn to reduce the risk of nitrate leaching. Agric. Water Manage. 199, 61, 2018.

18. XIA L., LAM S.K., CHEN D. Can knowledge-based $\mathrm{N}$ management produce more staple grain with lower greenhouse gas emission and reactive nitrogen pollution? A meta-analysis. Glob. Change Biol. 23, 1917, 2017.

19. NEVENS F., REHEUL D. Crop rotation versus monoculture; yield, $\mathrm{N}$ yield and ear fraction of silage maize at different levels of mineral $\mathrm{N}$ fertilization. NJAS-Wageningen Journal of Life Sciences. 4, 405, 2001.

20. KELLY K.W., LONG J.H., JR T.C. Long-term crop rotations affect soybean yield, seed weight, and soil chemical properties. Field Crops Research. 83, 41, 2003.

21. HE H.M., LIANG P., ZHANG Y. Test results of cotton N, P, K fertilizer utilization ratio. Second corps youth technology BBS proceedings. 106, 2012.

22. ZHANG Y.P., RONG X.M., LIU Q. Effects of fertilizer combining organic with inorganic on nutrient utilization and loss of nitrogen and phosphorus in dry land. J. Soil Water Conserv. 27, 48, 2013.

23. DIAZ R.J., SOLOW A. Ecological and Economic Consequences of Hypoxia: Topic 2 Report for the Integrated Assessment on Hypoxia in the Gulf of Mexico. NOAA Coastal Ocean Program, Decision Analysis Series. 16th edn. United States Department of Commerce, Washington, DC. 1999.

24. HA N., FEIKE T., BACK H. The effect of simple nitrogen fertilizer recommendation strategies on product carbon footprint and gross margin of wheat and maize production in the North China Plain. J. Environ. Manag. 163, 146, 2015.

25. DUAN X.L., FAN X.P., ZHANG F.L. The law of nutrient loss of nitrogen and phosphorus in surface runoff of rice field in Hubei province. Hubei Agricultural Sciences. 8, 3953, 2012.

26. LIANG X.Q., LIN L.M., YE Y.S. Nutrient removal efficiency in a rice-straw denitrifying bioreactor. Bioresour. Technol. 198, 746, 2015.

27. ZHAO M.X., ZHOU J.B., YANG R. Effects of different nitrogen application on nitrogen accumulation, transportation and distribution of different varieties of winter wheat in dry land. J. Plan. Nutri. Fertil. 2, 2143, 2006.

28. ZHONG Q., JU X.T., ZHANG F.S. The stress analysis of nitrogen environment in winter wheat/summer maize rotation system in north China plain. J. Plan. Nutri. Fertil. 3, 285, 2006. 
29. XU S.B. Nitrogen leaching characteristics of farmland in Jinan yellow river diversion irrigation area. Master of Engineering thesis, Jinan (China): University of Jinan. 2016.

30. Standard for groundwater quality. Beijing: China standard press. https://www.spc.org.cn/online/ GB\%252FT\%252014848-2017/ (accessed 5 June 2018).

31. XU X.J. Study on the risk of nitrogen and phosphorus loss in different crops and crop rotation in suburban Shanghai. PhD thesis, Beijing (China): Chinese Academy of Agricultural Sciences. 2007.

32. MALHI S.S., BRANDT S.A., LEMKE R. Effects of input level and crop diversity on soil nitrate-N, extractable $\mathrm{P}$, aggregation, organic $\mathrm{C}$ and $\mathrm{N}$, and nutrient balance in the Canadian. Prairie Nutr. Cycling Agroecosyst. 1, 1, 2009.

33. MOURI G., TAKIZAWA S., OKI T. Spatial and temporal variation in nutrient parameters in stream water in a ruralurban catchment, Shikoku, Japan: effects of land cover and human impact. J. Environ. Manage. 7, 1837, 2011.

34. SIMS J.T., SIMARD R.R., JOERN B.C. Phosphorus loss in agricultural drainage: Historical perspective and current research. J. Environ. Qual. 27, 277, 1998.

35. TANG L.H., LEI H.M., LIU X.B. Effects of agricultural activities on groundwater quality in Weishan irrigated region. Water Resources Protection. 5, 33, 2010.
36. Liaocheng statistical yearbook. Available online: http://tjj. liaocheng.gov.cn/tjsj/ndsj/201811/t20181101_1881220.html (accessed 6 June 2018).

37. ANDRASKI T.W., BUNDY L.G., BRYE K.R. Crop management and corn nitrogen rate effects on nitrate leaching. J. Environ. Qual. 29, 1005, 2000.

38. CHEN J.P., KE Z., MA J.Y. Study on the utilization rate of nitrogen and phosphorus in wheat in Sanmen county. Modern Agricultural Science and Technology. 6, 11, 2015.

39. GUO Z., LIU H.J., ZHANG Y.F. Effects of nitrogen and phosphorus on photosynthetic characteristics, yield and nitrogen utilization rate of rice sword leaf. Southwest China Journal of Agricultural Sciences. 10, 2263, 2017.

40. DU J., LI H.E., LI J.K. Based on the output coefficient analysis of the measured data and the non-point source load source of Feng river basin in Shanxi province. Journal of Agro-Environment Science. 4, 827, 2013.

41. MA H., BO H.B., CAI J.F. Analysis of nitrate nitrogen pollution in typical farmland groundwater of Weishan irrigation. Yellow River. 10, 105, 2012.

42. DING S. Study on nitrogen leaching process and groundwater pollution in Weishan irrigation region. Master of Engineering thesis, Beijing (China): Tsinghua University. 2010. 